\title{
Resenha
}

\section{Lev Vigotski - Coleção de vídeos de autoria de Marilene Proença e Marilda Facci: à guisa de resenha}

\author{
Lev Vigotski - a video collection: by way of review
}

Lev Vigotski - colección de videos: a modo de reseña

Souza, M. P. R., \& Facci, M. (Orgs.). (2011). Lev Vigostski [DVD - Coletânea 4 vols.]. São Paulo: Atta Mídia e Educação.

\begin{abstract}
A primeira questão é se caberia denominar de resenha algo que se refere a uma coleção de filmes. Recorrendo ao Dicionário Houaiss da Língua Portuguesa, encontramos para "resenha", entre outras definições, "(...) descrição feita com detalhes, com pormenores; (...) análise crítica ou informativa de um livro (...)", e como sinônimos: "(...) descrição, notícia, panorama (...)". Este texto pretende ser uma descrição, com vistas a informar, dar notícia, traçar um panorama dos vídeos e, ainda, um ensaio de análise. Embora uma das definições refira-se a livro, as demais não impõem esse limite. Acredita-se, assim, não ser inadequado considerar este texto como uma resenha.
\end{abstract}

\section{Apresentação dos vídeos}

A coleção compõe-se de quatro DVDs, com os seguintes títulos e tempo de duração de cada um dos volumes:

(1) Questões históricas e metodológicas [26m15s; quatro capítulos: Uma nova psicologia; Vigotski: biografia; Importância da escola e Fundamentos teóricos].

(2) O desenvolvimento do psiquismo [cinco programas: (a) Medicalização: respostas biológicas para questões sociais, com 16m07s; (b) Funções psicológicas superiores, com 21m21s; (c) A neuropsicologia e a visão luriana, com 14m41s; (d) A emoção e o processo educativo, com $11 \mathrm{~m} 31 \mathrm{~s}$, e (e) Periodização do desenvolvimento humano, com 16m46s].

(3) Implicações educacionais da psicologia histórico-cultural - PHC [cinco programas, a saber: (a) A escola e a socialização dos conhecimentos, com 13m35s; (b) Relação entre desenvolvimento e aprendizagem, com 22m18s: (c) PHC e o psicólogo escolar, com 16m59s; (d) PHC e a matemática, com 17m53s, e (e) Projeto político-pedagógico, com $16 \mathrm{~m} 35 \mathrm{~s}]$.

(4) Educação especial e queixas escolares [quatro programas: (a) A inclusão em uma sociedade socialista, com 19m56s; (b) Defectologia, com 20m41s; (c) A queixa escolar e a atuação do psicólogo, com 18m34s, e (d) Avaliação das queixas escolares, com 19m01s].

Os vídeos são constituídos por entrevistas, dirigidas por suas autoras, Marilene Proença e Marilda Facci, que se apresentam mais como diálogo e debate entre entrevistador e entrevistado, imprimindo uma dinâmica e uma vivacidade que tornam os filmes fluidos e interessantes. Além disso, os vídeos são ilustrados com efeitos visuais e fotos, que dão leveza ao filme e constituem-se em elemento didático importante para a compreensão de conteúdos complexos, difíceis e, principalmente, que tentam mostrar a dialeticidade implicada na teoria e em sua mediação com os temas tratados. Esse é o motivo porque se defende que essa coleção de 
vídeos tem um inestimável valor para o ensino da psicologia e para a formação de professores.

\section{Conteúdos}

Os dois primeiros volumes abordam questões teóricas e os demais, as implicações práticas da teoria, mas isso não ocorre de maneira dicotômica, cumprindo-se a difícil tarefa de estabelecer, a cada passo, as articulações entre os fundamentos epistemológico-metodológicos do materialismo histórico-dialético - MHD, as bases teóricas da PHC e as implicações práticas relativas, sobretudo, à educação e aos processos de escolarização.

Há uma crítica recorrente de que produções intelectuais que se definem como sustentadas no método do MHD nem sempre o são de fato, não conseguindo incorporar em seu processo de elaboração e exposição as categorias e as mediações necessárias para que possam proclamar-se como tal. Não é o caso da coleção Lev Vigotski. Há, pelo contrário, uma espiral dialética, em que sistematicamente volta-se para as categorias da $\mathrm{PHC}$ e, principalmente, para a base do MHD, com especial destaque para a historicidade como condição para a compreensão do psiquismo em sua concreticidade. Só esse motivo já é suficiente para se afirmar que esses vídeos trazem uma contribuição ímpar para o campo da psicologia e para a difusão responsável da teoria.

Seguem abaixo a descrição e um breve ensaio analítico de cada um dos volumes da coleção Lev Vigotski.

\section{Volume 1: Questões históricas e metodológicas}

Um dos principais problemas que cercam a difusão da PHC é o aligeiramento de conceitos e categorias, que deturpam a teoria e, por consequência, as práticas que supostamente nela se sustentam. Além do problema das traduções em português, é principalmente o desconhecimento dos fundamentos epistemológico-metodológicos, a base materialista histórico-dialética, que produz interpretações equivocadas, superficiais e inconsequentes, que oscilam entre uma visão idealista e uma visão mecanicista (tão extensiva e profundamente criticadas por Vigotski), com sérias implicações para a práxis educativa e para o desenvolvimento da teoria. É nesse aspecto, o de apresentar uma breve, mas consistente, exposição desses fundamentos, que esse vídeo mostra seu diferencial. Não se limita, porém, a esse aspecto, mas, como já foi dito, essa fundamentação é chamada em todos os programas para explicar a teoria e empreender as mediações entre esta e as práticas em discussão.

O vídeo é constituído por quatro capítulos: Uma nova psicologia; Vigotski: biografia; Importância da escola e Fundamentos teóricos. Não há uma entrada específica para cada capítulo; eles são tratados em sequência, o que permite ao espectador acompanhar a articulação entre eles. São abordadas três grandes questões, que são necessárias para se compreender a gênese da teoria: a defectologia tal como proposta por Vigotski; a psicologia geral, a cultura e o papel da educação; a psicologia para a construção de uma nova sociedade. Esse vídeo traz entrevistas com Silvana Calvo Tuleski e Marta Ofélia Shuare, que contribuem para explicitar os fundamentos do MHD e a realidade histórica na qual esse pensamento foi engendrado, que tem como projeto a construção de uma nova sociedade, projeto este que está na base da PHC. Deve-se sublinhar que, para cada um dos temas tratados, é destacado um texto de Vigotski no qual estes são trabalhados. Chama a atenção também a beleza das imagens que mostram a realidade histórica na qual a teoria se constituiu, a Revolução Russa.

\section{Volume 2: O desenvolvimento do psiquismo}

Esse vídeo é composto por cinco programas. O primeiro programa, Medicalização: respostas biológicas para questões sociais, baseia-se numa entrevista com Helvio Moisés, que expõe uma história crítica da biologia que floresce em meados do século XIX. É uma exposição muito clara e interessante, sem correr o risco de perder a profundidade e a complexidade do tema. Outra entrevista, com Nádia Mara Eidt, aborda o problema do Transtorno do Déficit de Atenção com Hiperatividade - TDAH, explicitando as duas abordagens vigentes: organicista e histórico-cultural, com as implicações que cada uma tem para o desenvolvimento e para o processo de escolarização de crianças que têm sido "diagnosticadas" com esse "transtorno".

O segundo programa do vídeo aborda as Funções psicológicas superiores e compõe-se de entrevista com Lígia Márcia Martins que expõe o fundamento teórico-metodológico que afirma a interação social e a cultura, em contraposição às ideias que postulam a maturação biológica como determinante do desenvolvimento das funções psicológicas superiores.

O programa A neuropsicologia e a visão luriana é apresentado por Silvana Tuleski e trata da relação entre a neuropsicologia e a educação. A entrevistada mostra que Luria posicionou-se contra o "localizacionismo", defendendo a ideia de sistemas funcionais no desenvolvimento psiconeurológico humano. É tratado o déficit de atenção e como a escola pode contribuir para o desenvolvimento da atenção voluntária.

O quarto programa é $A$ emoção e o processo educativo, tendo Gisele Toassa como entrevistada. Mostra as emoções como função psicológica complexa, que se inter-relaciona com a memória, a atenção e outras funções, articulando as questões relacionadas à emoção e ao sentimento com os processos de escolarização, acenando para a importância dessas formulações para a construção de um projeto de educação. É muito interessante a relação que Toassa faz entre educação, arte e desenvolvimento das emoções. Por sua relevância, esse tema merece um vídeo específico.

O último programa do vídeo, Periodização do desenvolvimento humano, tendo como entrevistada Marilda Facci, trata de um tema necessário e recorrente nas discussões 
sobre a PHC, em geral tratado superficialmente. São abordados os conceitos de desenvolvimento, atividades principais, adolescência e crise e fase adulta. Facci parte de Marx, para quem as "mudanças nas condições concretas de vida mudam o homem", desenvolvendo o conceito de atividades principais ou dominantes, elaborado por Leontiev e Elkonin, como atividades que governam a vida da criança num dado momento de sua vida, "no sentido de guiar o desenvolvimento psicológico". Esse tema merece, como o anterior, um vídeo específico, pois é uma questão pouco discutida e cercada de equívocos.

Volume 3: Implicações educacionais da psicologia histórico cultural

O terceiro vídeo é composto por cinco temas. No primeiro vídeo, A escola e a socialização dos conhecimentos, é entrevistado Newton Duarte, que trata das relações entre a PHC e MHD, fazendo um cotejamento entre a PHC , a epistemologia genética e a formação do indivíduo, com ênfase na categoria trabalho. Duarte contrapõe a $\mathrm{PHC}$ à epistemologia genética de Piaget, tratando da atividade humana, da relação trabalho e alienação, além do compromisso com a transformação da sociedade capitalista em sociedade socialista.

O segundo tema é a Relação entre desenvolvimento e aprendizagem, cuja entrevistada é Marilda Facci. São abordados os temas: zona de desenvolvimento próximo; conteúdo, apropriação e desenvolvimento; Vigotski e Piaget e compromisso político. Esse programa apresenta questões essenciais como base teórica para a atuação do professor e suas implicações para a superação de muitos dos problemas recorrentes da escola e do processo de escolarização. Essa concepção de psicologia é relacionada à pedagogia histórico-crítica, relação esta necessária para o entendimento dessa proposta teórico-prática. O vídeo traz ainda uma entrevista com a professora Marta Chaves, na escola, explicitando as implicações da teoria em sua prática pedagógica.

O terceiro tema é PHC e o psicólogo escolar, que trata das contribuições da teoria para a psicologia escolar e da PHC e a educação, com base em entrevista com Marisa Meira. Entende o objeto da psicologia escolar como o encontro entre sujeito humano e educação, sem perder a perspectiva da psicologia e com o olhar para a prática educativa. A entrevistada fala de alguns mitos em educação, mostrando como os pressupostos vigotskianos podem desfazê-los e contribuir para a superação dos problemas da educação.

O quarto tema compõe-se de entrevista com Manoel Oriosvaldo de Moura e trata da PHC e a matemática, abordando os pressupostos da PHC e a didática; didática e conteúdo; historicidade e atividade orientadora de ensino. Discorre sobre vários conceitos da PHC, demonstrando sua articulação com o ensino da matemática. A entrevista é uma das mais interessantes, principalmente porque aborda o ensino da matemática, uma área que é tradicionalmente problemática na educação e, além disso, por se tratar de tema ainda pouco trabalhado no âmbito dessa abordagem da psicologia. Esse tema é outro que merece ser aprofundado nos próximos vídeos, com a sugestão de que outras áreas do conhecimento possam também ser trabalhadas a partir da $\mathrm{PHC}$, o que se constituiria num recurso extremamente rico para a formação de professores, além de ser uma contribuição efetiva para a ampliação do conhecimento na área.

Por fim, o vídeo trata do tema Projeto político-pedagógico, sendo entrevistada Flávia Asbahr, que aborda os conceitos de significado e sentido na atividade pedagógica e sua relação com a elaboração e implementação do projeto político-pedagógico. Asbahr discorre sobre a cisão entre significado e sentido na atividade docente, abordando o problema do adoecimento do professor e a fragmentação de sua consciência.

\section{Volume 4: Educação especial e queixas escolares}

Se os três primeiros vídeos são indiscutivelmente relevantes para a difusão da $\mathrm{PHC}$ com precisão terminológica e conceitual, esse último vídeo vem, além disso, suprir a carência de recursos que discutam e articulem as questões relacionadas ao educando com deficiência.

O primeiro programa, coerente com a perspectiva que atravessa toda a coleção de vídeos, introduz o tema a partir da história, explicitando a gênese dessa formulação, com o título $A$ inclusão em uma sociedade socialista, na entrevista com Sonia Shima e Maria Ângela Bassan Sierra.

Em seguida é tratada a Defectogia, tendo como entrevistado Guillermo Arias Beatón, que explana sobre os pressupostos gerais para a educação das pessoas com ou sem deficiência, o que permitiria a inclusão plena. Ênfase é dada aos recursos mediadores, que regem o desenvolvimento humano - para todos - por meio dos instrumentos culturais. Para ele, é necessário considerar o desenvolvimento em sua integralidade como fundamento para uma educação que permita à criança aprender e a se desenvolver.

O terceiro programa é A queixa escolar e a atuação do psicólogo, em que Marilda Facci é entrevistada por Marilene Proença. Um dos temas expostos é a avaliação psicológica, pois esta é uma demanda recorrente dos encaminhamentos da escola para o psicólogo. Defende-se a avaliação do processo e não do produto, com base numa análise explicativa e não descritiva, procurando identificar que mediações foram realizadas com a criança para apreender o processo de desenvolvimento das funções psicológicas superiores. Entendem que avaliar é considerar as relações entre desenvolvimento e aprendizagem, as funções psicológicas superiores e o desenvolvimento próximo, num processo que deve ser dialogado, com a participação da criança, pais e professores.

Marilene Proença fala, em seguida, sobre a Avaliação das queixas escolares. Propõe, para isso, uma visão ampliada, em oposição à visão organicista e medicalizante, devendo-se questionar o que a escola está oferecendo para essa criança para que ela não se beneficie de seus recursos. É preciso investir na aprendizagem, já que é esta que produz o desenvolvimento. Esse programa tem relevância 
para a educação e explicita formulações que, se apropriadas por professores, certamente produzirá um impacto significativo no processo de escolarização. As ideias apresentadas nesse programa prestam um grande serviço à educação, demonstrando as relações entre aprendizagem e desenvolvimento, em que a primeira produz a última, contrapondo-se e invertendo os polos da questão, cujas implicações podem ser consideradas revolucionárias em educação.

\section{Considerações Finais}

Essa coleção de vídeos vem satisfazer uma demanda já antiga na área. Um dos maiores problemas que a psicologia escolar e a psicologia educacional enfrentam é o recorrente aligeiramento teórico, cuja implicação na educação é por todos sabida. Autores e conceitos são utilizados de maneira vaga e, não poucas vezes, erroneamente. O maior problema enfrentado por essa abordagem é o "consumo" da teoria ou, melhor dizendo, de conceitos fragmentados, confundidos e mesclados ao senso comum, com o pior de todos os agravantes, que é o desconhecimento dos fundamentos epistemológicos e metodológicos, sem os quais não é possível afirmar que se trata de fato da PHC. Vieses idealistas ou mecanicistas são recorrentes mesmo entre pesquisadores e educadores que se dedicam à abordagem. Não é possível a compreensão da teoria histórico-cultural sem a base teórico-metodológica do materialismo histórico e dialético.
Essa é uma das mais importantes contribuições desse trabalho. Em cada programa as categorias são retomadas e concretizadas em cada conceito ou implicação prática discutida. Há uma preocupação recorrente em cada entrevista com os fundamentos dos conceitos trabalhados. Só esse motivo é suficiente para afirmar a relevância desse trabalho. Mas há outros. Já foi discutida a importância desse recurso para o ensino da psicologia. Mas há também outra possibilidade (ou necessidade) de uso desses vídeos: a formação de professores.

Extrapola o âmbito de uma resenha, mas a sugestão é de que esses vídeos pudessem ser adquiridos por secretarias de educação, estaduais e municipais, embora não baste apenas passá-los aos professores, mas serem trabalhados por profissionais com domínio teórico para serem exaustivamente cotejados com a realidade de sala de aula. Creio que, assim, se cumpre a finalidade que, embora não expressa, é um dos motivos pelos quais esses vídeos foram produzidos.

Para finalizar, como já foi dito na análise de cada um dos capítulos, essa coleção deve ser continuada, explorando outros aspectos e aprofundando algumas questões que são de relevância para a difusão do conhecimento e como fundamento para a prática educativa.

Recebido em: 24/06/2013

Aprovado em: 29/06/2013

\section{Sobre a autora}

Mitsuko Aparecida Makino Antunes (miantunes@pucsp.br)

Professora do Departamento de Fundamentos da Educação da Pontifícia Universidade Católica de São Paulo, atuando no Programa de Estudos Pós-graduados em Educação: Psicologia da Educação.

Endereço para correspondência: Rua Ministro Godoi, 969, Perdizes - CEP - 05015-901 - São Paulo, SP - Brasil. 